\title{
Contribution to the Investigation of Motorcyclists' Speed Prediction Equations for Two-Lane Rural Roads
}

\author{
Panagiotis V. Lemonakis ${ }^{1}$, Nikolaos E. Eliou ${ }^{1}$, George N. Botzoris ${ }^{2}$, Theodoros E. Karakasidis ${ }^{1}$ \\ ${ }^{1}$ Department of Civil Engineering, Section of Transportation, University of Thessaly, Volos, Greece \\ ${ }^{2}$ Department of Civil Engineering, Section of Transportation, Democritus Thrace University, Xanthi, Greece \\ Email: plemonak@gmail.com,neliou@civ.uth.gr,gbotzori@civil.duth.gr, thkarak@civ.uth.gr
}

Received March 21, 2013; revised April 22, 2013; accepted April 30, 2013

Copyright (C) 2013 Panagiotis V. Lemonakis et al. This is an open access article distributed under the Creative Commons Attribution License, which permits unrestricted use, distribution, and reproduction in any medium, provided the original work is properly cited.

\begin{abstract}
The calculation of speed prediction equations has been the subject of numerous researches in the past. The majority of them present models to predict free-flow speed in terms of the road geometry at the curved road sections and more specifically in terms of the radiuses of the curves. Common characteristic is that none of them approaches the speed behavior of motorcycles since they are excluded from the datasets of the various studies. Instead, the models usually predict operating speed for other vehicle types such as passenger cars, vans, pickups and trucks. The present paper aims to cover this gap by developing speed prediction equations for motorcycles. For this purpose a new methodology is proposed while field measurements were carried out in order to obtain an adequate dataset of free-flow speeds along the curved sections of three different two lane rural roads. The aforementioned field measurements were conducted by two participants incorporating various road conditions (e.g. light conditions, experience level, familiarity with the routes). The ultimate target was the development of speed prediction equations by calculating the optimum regression curves between the curve radius' and the corresponding velocities for the different road conditions. The research revealed that the proposed methodology could be used as a very useful tool to investigate motorcyclists' behavior at curved road sections. Moreover it was feasible to draw conclusions correlating the speed adjustment with the various driving conditions.
\end{abstract}

Keywords: Motorcyclists’ Behavior; Regression Curves; Curvature; Free-Flow Speed; Speed Equations; Field Measurements

\section{Introduction}

Numerous studies have been carried out during the last decades in the field of road safety in order to predict the relationship between driver behavior and road features (especially on horizontal curves). Many of these studies focus on creating analytical models expressing driver behavior in relation to the characteristics of the roads [1-7]. In these models, driver behavior is expressed by the operating speed $\left(\mathrm{V}_{85}\right.$, that represents the 85th-percentile speed), while the road characteristics are generally represented by the curvature change rate of the single curve or the horizontal curve radius, since it has been estimated that the magnitude of the radius of the horizontal curves is the most considerable factor that determines operational speed [8]. Nevertheless, the true effect of each individual geometric variable (e.g. curve radius, length of the curve, deflection angle and superelevation) is still not known precisely in quantitative terms [9].
As stated in a recent study [10], most models developed to date focus on passenger car speeds. However, the speed behavior of motorcycles was studied by [11], evaluated the possibility to develop a motorcycle operating speed prediction model analyzing the relationships between the motorcycle operating speed and the passenger cars operating speed. Both motorcycle and vehicle speeds were collected using a Light Detection and Ranging (Lidar) gun while graphic as well as statistical analysis followed the measurements. The outcome of this research was the development of the Equation (1):

$$
V_{85 P T W}=1.162 \cdot V_{85 P C}, R^{2}=0.94
$$

where

$V_{\text {85PTW: }}$ the 85 th percentile speed on tangent of powertwo-wheelers $(\mathrm{km} / \mathrm{h})$,

$V_{85 P C}$ : the 85 th percentile speed on tangent of passenger cars $(\mathrm{km} / \mathrm{h})$,

$R^{2}$ : the coefficient of determination. 
The objective in another study by [12] is to develop a speed prediction equation on horizontal curves using the geometric characteristics of the curves at 11 sites in exclusive motorcycle lane. To achieve this objective, the speeds of motorcyclists were measured in exclusive motorcycle lanes in Malaysia using two devices; a portable laser speed detector and a digital video camera. The authors of this study using linear regression procedure, in order to identify the best fit combinations of the independent variables, developed the following Equation (2):

$$
V_{85, \text { curve }}=19.357 \cdot \mathrm{W}-0.394 \cdot \Delta+0.654 \cdot T
$$

where

$V_{85 \text {,curve }}$ : the 85 th percentile motorcycle speed on horizontal curves,

$W$ : the total lane width,

$\Delta$ : deflection angle,

$T$ : the length of tangent.

No other study relevant to motorcycle speed prediction equations has been carried out apart from the two afore-mentioned ones, at least to our knowledge. Therefore the impact of the different light conditions, the different experience level, the familiarity with the road and the different road environment to drivers' behavior expressed in operating speed changes can only be observed in passenger cars studies.

The investigation of motorcyclists' speed prediction equations at the present study has been achieved by proposing a new methodology of measuring speeds based on GPS technology which preceded the conduction of field measurements in order to in order to obtain an adequate dataset of free-flow speeds. The field measurements were designed taking into account various factors that potentially influence the riders' behavior such as the different light conditions, the difference on the riding experience level, the familiarity of the riders with the routes, the presence of pillion and the different road environments, such as width/condition of the road pavement, roadside land use, etc.

\section{Experimental Design of the Field Measurements}

\subsection{Participants}

Initially, three basic parameters had to be defined with regards to the participants' selection that would execute the field measurements; demographic criteria, riding experience and psychometric aspects of the riders [13].

The choice of the participants' gender was based on preceding researches which have shown that males are over-represented both in car and motorcycle accidents $[14,15]$, but also in the riding population even though they do not necessarily demonstrate riskier behaviors. Moreover, males constitute the typical rider gender and they can be recruited easier than the female ones.

Experience is also a significant factor that determines the level of risk taking behavior among riders. In most of the cases, there is a correlation between riding experience and age, since young riders are more inexperienced in comparison to the older ones who are more experienced. In order to reduce the probability of accident occurrence during the experiment, young and older riders were excluded, due to their high risk rates. Consequently, all participants had to have an actual riding experience of at least 5 years and should not be older than 50 years old. Aiming also to the latter target, the sample of riders was biased towards riders with limited accident records. Furthermore, since one of the main objectives of the present research was to determine how the riding experience affects riding behavior, efforts were made in order to match the overall participants' features apart from their riding experience, which was selected to be considerably different.

Another issue that had to be dealt with was that the riders had to achieve a certain level of familiarity with the instrumented motorcycle. For that reason, prior to the execution of the field measurements, the riders were asked to ride the experimental motorcycle until they felt confident with its operation. It should also be noted that the demands for adequate handling were relatively increased due to the size and weight of the instrumented motorcycle.

Taking under consideration the afore-mentioned, two male riders belonging at the same age group were selected to carry out the field measurements. None of them revealed any obvious reason of impaired riding ability while their riding experience levels were totally different. Moreover, they had common stay of residence, adjacent to the routes where the experiment was conducted and therefore, they both had similar familiarity with the experimental environment.

\subsection{Instrumented Vehicle and Record Devices}

Many researchers have obtained speed data, using in most cases, a radar gun $[16,17]$ as well as speed detectors [12]. Both methods can introduce errors such as measuring errors or can influence drivers' behavior who might perceive the speed record equipment and hence, adjust their speeds to the legal speed limits of the sections studied [10]. Therefore in order to overcome the shortcomings of the speed recording equipment that has been used so far we established a new speed record method which was based on the usage of GPS data logger.

Data loggers can record GPS, video and vehicle data and are ideally suited to motorsport due to their small weight, size and increased accuracy. Moreover without fitting any other sensors, the measure of speed, track po- 
sition, distance, lap time, lateral acceleration, longitudinal acceleration and height is feasible. Recording of such parameters can be particularly useful especially in cases where driving behavior is not approached exclusively in speed terms. In addition, by using a single record system it is possible to investigate the behavior of the riders in multiple curves, since the various equipment are attached onto the vehicle instead of the road.

In this view the equipment that was used to record the relevant with the riding performance parameters, such as position and velocity was the Video Vbox from Racelogic Company. The Video Vbox combines a powerful GPS data logger with a high quality solid-state video recorder. In order to capture the video file, it is equipped with two cameras and two microphones whilst records the following parameters as standard along with the video file: satellites, time, latitude, longitude, velocity, heading, height and vertical velocity.

The videos, as well as the data files are saved onto an SD card. The logging rate is ten samples per second, which was considered as adequate enough to cover the needs of the experiment. As an example, an 8-gigabyte high capacity SD card, logging video on the highest quality setting was able to log approximately $160 \mathrm{~min}$ utes of video. Apparently, this is an approximation, as the size of the recorded video depended on what was being recorded. The motion, color and complexity of the subject matter affected the size of the video file created. It should also be mentioned that the size of the data file was particularly small, in comparison to the size of the video file. The recorded data were downloaded daily right after the execution of the experiment from the flash memory to an external High Capacity HD that was given to the riders.

The primary specifications of the record device are summarized in Table 1 and the accuracies of the recorded quantities are indicated in Table 2.

Lastly, the instrumented bike that was used to carry out the field measurements was an on/off motorcycle, widespread on rural roads especially because of its ability to provide sufficient transport on asphalt, as well as on soil material surfaces. The primary specifications of the instrumented motorcycle are summarized in Table 3.

\subsection{Location, Type of Roads, Weather Conditions, Time of Day}

The selection of the experimental environment had to be based upon four primary conditions: the location, the type of the road, the weather conditions and finally, the time and date that the experiment would be conducted. All of these four conditions had to be common for both riders in order to record comparable data.

The location of the experiment should ensure on one hand the constant function of the recording device, and
Table 1. Specifications of equipment video vbox.

\begin{tabular}{ll}
\hline Video file & MPEG-4 \\
$\begin{array}{l}\text { Recording } \\
\text { options }\end{array}$ & $\begin{array}{l}\text { - Record only when moving (default), } \\
\text { - Record start/stop via optional remote switch. }\end{array}$ \\
$\begin{array}{l}\text { Camera } \\
\text { inputs }\end{array}$ & $\begin{array}{l}2 \times \text { AV camera inputs (camera supplied as option) } \\
\text { with integrated } 12 \mathrm{~V} \text { power supplies }\end{array}$ \\
Graphics & 24 bit color - DVD $720 \times 576$ at 25 frames $/$ sec or \\
& DVD $720 \times 480$ at 30 frames $/$ sec resolution options \\
Sound & $-2 \times$ external microphone connections, \\
Storage & - MP2 (MPEG1 Layer II) encoded video stream. \\
options & SD Card \\
\hline
\end{tabular}

Table 2. Accuracies of equipment video vbox.

\begin{tabular}{lc}
\hline \multicolumn{1}{c}{ Parameter } & Accuracy \\
\hline Velocity & $\pm 0.2 \mathrm{Km} / \mathrm{h}$ \\
Distance & $\pm 0.05 \%$ \\
Position & $\pm 5 \mathrm{~m}$ \\
Height & $\pm 10 \mathrm{~m}$ \\
Lateral acceleration & $\pm 0.5 \%$ \\
Longitudinal acceleration & $\pm 0.5 \%$ \\
\hline
\end{tabular}

Table 3. Specifications of the instrumented motorcycle.

\begin{tabular}{lc}
\hline Category & Enduro/offroad \\
Displacement & $652.00 \mathrm{ccm}$ \\
Engine type & Single cylinder, 4-stroke \\
Power & $48.00 \mathrm{HP}$ \\
Torque & $57.00 \mathrm{Nm}$ \\
Top speed & $160.0 \mathrm{~km} / \mathrm{h}$ \\
0 - 100 km/h & $5.20 \mathrm{~seconds}$ \\
60 to 140 km/h, highest gear & $10.60 \mathrm{~seconds}$ \\
Cooling system & Liquid \\
Gearbox & 5 -speed \\
Transmission type & Chain \\
Front suspension travel & $170 \mathrm{~mm}$ \\
Rear suspension travel & $165 \mathrm{~mm}$ \\
Front tire dimensions & $100 / 90-19$ \\
Rear tire dimensions & $130 / 80-17$ \\
Front/rear brakes & Single disc \\
Brakes diameter & $199.0 \mathrm{~kg}$ \\
Weight incl. oil, gas, etc. & $820 \mathrm{~mm}$ \\
Seat height & $17.50 \mathrm{liters}$ \\
Fuel capacity & Electric \\
Starter & \\
\hline & Front: $300 \mathrm{~mm}, \mathrm{Rear}: 240 \mathrm{~mm}$ \\
\hline &
\end{tabular}


on the other hand the presence of a large number of curved sections. Moreover, the traffic volumes should be particularly limited during the experiment in order to achieve unaffected riding behavior. Finally, for purely practical purposes, the experimental environment was sought close to the participants' place of residence. Taking into account the above-mentioned, the road network that would serve the needs of the research and meet the requirements of the experiment was mountain Pelion, in Magnesia, Central Greece. The road network of Pelion consists exclusively of intensive curved rural roads, which vary depending on its geometrical characteristics, the presence of vertical/horizontal signage and the pavement condition.

In a more detailed investigation, three road sections were determined as appropriate to carry out the field measurements (Figure 1). The evaluation of the appropriate experimental road sections is indicated in Table 4.

Regarding the weather conditions and in order to restrict the parameters that affect the riding behavior of the participants, both riders instructed to cease the measurements when the pavement was wet, even slightly. The natural lighting level should be constant and hence, during cloudy or foggy days the measurements were ceased as well. In general, the instructions that were given to the riders, forbidden the execution of the experiment in case any environmental or traffic conditions might divert their regular riding behavior. It is also noted that the unimpeded approach to the curves ensured by succeeding null traffic volumes. For that purpose the measurements were conducted when the road was free from the presence of other road users.

Aiming at the investigation of the correlation between natural lighting and riding behavior, two different time periods were set for the execution of the experiment. The first one was set between 09:00 and 16:00 (constant natural lighting during autumn-daytime measurements) and the second one between 21:00 and 01:00 (nighttime measurements). Apparently, apart from the lighting conditions all the other environmental and weather conditions were equivalent for both time periods.

Apart from the investigation of the correlation between lighting conditions and riding behavior, another aim of the present research was the inquiry of the contribution of the familiarity with a road to the riding behavior. For that purpose the participants were asked to ride each one of the routes six times during daytime and six times during nighttime. Finally, after the completion of the twelve afore-mentioned measurements, the riders were asked to repeat each route once more with the presence of a pillion in order to investigate how this condition influences their riding behavior since the presence of a pillion affects firstly the total weight of the system rider/motorcycle and secondly it increases the sense of responsibility of the rider for the pillion's safety. In total, both riders conducted 78 measurements, as analytically shown in Table 5.

\section{Data Analysis}

The data analysis was based on three program packages; Vbox Tools v2.2.2 b042 of Racelogic, Excel 2007 of Microsoft and Autocad 2009 of Autodesk. The original data files recorded at the SD card (extension *.vbo) opened using Vbox Tools and then were simply converted to comma delimited files (extension *.csv). Each *.csv file corresponded to a specific measurement and contained 3 columns; velocity, coordinate $\mathrm{x}$ and coordinate $y$. It is reminded that these values were recorded at a sampling rate of $10 \mathrm{~Hz}$.

Table 4. Evaluation of the experimental routes.

\begin{tabular}{|c|c|c|c|}
\hline $\begin{array}{l}\text { Road section } \\
\text { (coordinates) }\end{array}$ & $\begin{array}{l}\text { Afyssos-Afetai } \\
\left(39^{\circ} 16^{\prime} 30.24^{\prime \prime} \mathrm{B},\right. \\
23^{\circ} 10^{\prime} 1.12^{\prime \prime} \mathrm{A} \text { to } \\
39^{\circ} 16^{\prime} 53.69^{\prime \prime} \mathrm{B}, \\
\left.23^{\circ} 10^{\prime} 41.10^{\prime \prime} \mathrm{A}\right)\end{array}$ & $\begin{array}{c}\text { Milina-Lafkos } \\
\left(39^{\circ} 10^{\prime} 6.58^{\prime \prime} \mathrm{B},\right. \\
23^{\circ} 13^{\prime} 43.97^{\prime \prime} \mathrm{A} \text { to } \\
39^{\circ} 10^{\prime} 0.43^{\prime \prime} \mathrm{B}, \\
\left.23^{\circ} 14^{\prime} 21.94^{\prime \prime} \mathrm{A}\right)\end{array}$ & $\begin{array}{c}\text { Neohori- } \\
\text { Kalamaki } \\
\left(39^{\circ} 18^{\prime} 43.98^{\prime \prime} \mathrm{B},\right. \\
23^{\circ} 12^{\prime} 49.28^{\prime \prime} \mathrm{A} \text { to } \\
39^{\circ} 19^{\prime} 23.41^{\prime \prime} \mathrm{B} \\
\left.23^{\circ} 11^{\prime} 45.51^{\prime \prime} \mathrm{A}\right)\end{array}$ \\
\hline Length & $2300 \mathrm{~m}$ & $2300 \mathrm{~m}$ & $2550 \mathrm{~m}$ \\
\hline $\begin{array}{c}\text { Curve radius } \\
\text { range } \\
\left(\mathbf{R}_{\min } / \mathbf{R}_{\max }\right)\end{array}$ & $11 \mathrm{~m} / 315 \mathrm{~m}$ & $24 \mathrm{~m} / 157 \mathrm{~m}$ & $49 \mathrm{~m} / 222 \mathrm{~m}$ \\
\hline $\begin{array}{c}\text { Total } \\
\text { pavement } \\
\text { width }\end{array}$ & $\begin{array}{c}5.20 \mathrm{~m}(2.60 \mathrm{~m} \\
\text { per direction })\end{array}$ & $\begin{array}{l}6.00 \mathrm{~m}(3.00 \\
\text { per direction })\end{array}$ & $\begin{array}{c}8.20 \mathrm{~m}(4.10 \mathrm{~m} \\
\text { per direction })\end{array}$ \\
\hline $\begin{array}{c}\text { Horizontal } \\
\text { signage }\end{array}$ & Absent & $\begin{array}{l}\text { Continuous single } \\
\text { line on the } \\
\text { centerline as well } \\
\text { as on the } \\
\text { boundaries of the } \\
\text { road }\end{array}$ & Yes \\
\hline $\begin{array}{l}\text { Vertical } \\
\text { signage }\end{array}$ & Absent & $\begin{array}{c}\text { Partially } \\
\text { (3 danger signs) }\end{array}$ & Yes \\
\hline Guard rails & Absent & Absent & Yes \\
\hline $\begin{array}{l}\text { Artificial } \\
\text { lighting }\end{array}$ & Absent & Absent & Absent \\
\hline $\begin{array}{l}\text { Pavement } \\
\text { condition }\end{array}$ & $\begin{array}{c}\text { Extensive } \\
\text { surfaces with } \\
\text { cracks, grooves } \\
\text { and subsidence }\end{array}$ & $\begin{array}{l}\text { Several spots with } \\
\text { transverse and } \\
\text { longitudinal } \\
\text { cracks, grooves } \\
\text { and layering of } \\
\text { bituminous seal }\end{array}$ & Excellent \\
\hline Evaluation & Poor & Satisfactory & Excellent \\
\hline
\end{tabular}

Table 5. Amount and description of measurements.

\begin{tabular}{ccccc}
\hline Condition & $\begin{array}{c}\text { Number } \\
\text { of routes }\end{array}$ & $\begin{array}{c}\text { Number of } \\
\text { repetitions }\end{array}$ & $\begin{array}{c}\text { Number } \\
\text { of riders }\end{array}$ & Total \\
\hline Daytime & 3 & 6 & 2 & 36 \\
Nighttime & 3 & 6 & 2 & 36 \\
Pillion & 3 & 1 & 2 & 6 \\
& Total amount of measurements & & $\mathbf{7 8}$ \\
\hline
\end{tabular}



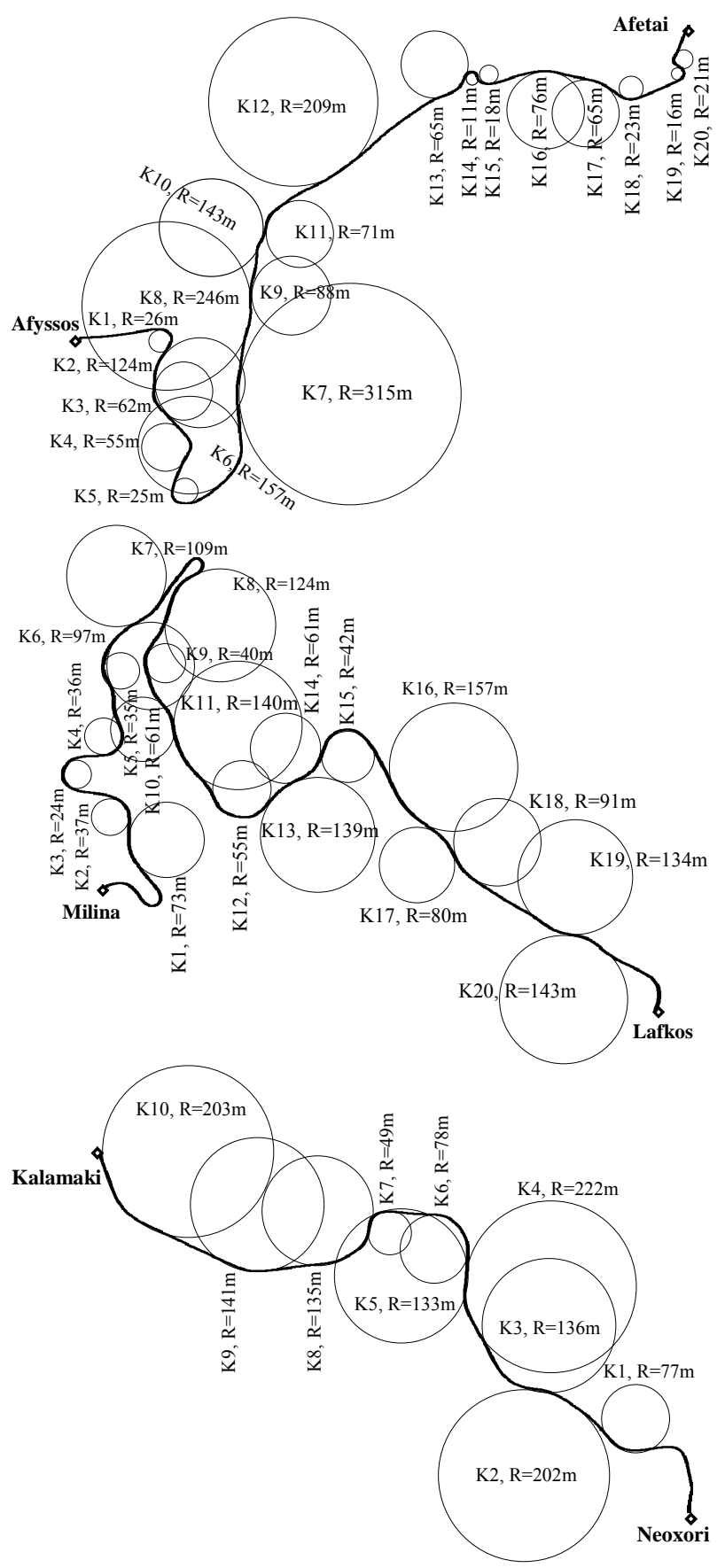

Figure 1. Experimental road sections.

Since coordinates $\mathrm{x}$ and $\mathrm{y}$ were known the design of the trajectory of each measurement was feasible in Autocad using the appropriate lisp (functional language). Moreover, a number was assigned in each pair of $\mathrm{x}$ and $\mathrm{y}$ coordinates in ascending order, starting from number 1 for the first recording. Apparently, the last number varies among the measurements since it derives from the total time that each measurement completed.

Apart from the design of the trajectory of each measurement, it was also drawn a representative rendering of the line of each route and its geometrical characteristics and especially the edge of the traveled way (reference arc) that none of the riders encroached in each curve. The radius that refers to each reference arc was then used to the analysis that followed. Hence the results and conclusions of the present research were not based upon the geometrical radius of the curves and thus cannot be used as evaluation criteria of design consistency.

The knowledge of the beginning and end of each curve (different numbers for each measurement as implied below) led to the determination of the beginning and end number for each curve and measurement. Thereafter by simply averaging the velocities within the beginning and end number we calculated the mean velocity (apparently for each curve and measurement). It is noted that the velocity of each measurement at the beginning and end of each curve was calculated with linear regression of the values right before and right after the curve implying that the trajectory and hence the variation of the velocity between two consecutive points, is linear.

By this means the calculation of the mean velocities in each curve for each one of the 78 different measurements was possible. More specifically, 50 curves were determined for further analysis; 20 curves located at route Afyssos-Afetai ( 9 curves were right hand while 14 curves had radius $\mathrm{R}<100 \mathrm{~m}$ ), 20 curves located at route Milina-Lafkos (10 curves right hand, 13 curves with radius $\mathrm{R}<100 \mathrm{~m}$ ) and 10 curves located at route Neohori-Kalamaki ( 6 curves right hand, 3 curves with radius $\mathrm{R}<100 \mathrm{~m}$ ).

The next step of the data processing method was to determine the method to calculate the equations that correlate the recorded velocities with the corresponding radiuses of the horizontal curves as defined above. Previous research has shown that linear regression can be used to predict operating speeds on circular curves. The results of researches as discussed in a study conducted by [18] showed that the 85th percentile speeds on horizontal curves (the dependent variable) can be predicted using combinations of independent variables such as curve radius, length of the curve, deflection angle, and superelevation. Apart from the afore-mentioned studies, it was evident that the ordinary least square (OLS) regression was the most widespread model type among the various researchers that has been used in order to develop comprehensive speed prediction equations/models and for that reason it was selected against other model types [10].

\section{Results}

The calculation of the mean velocities followed by the implementation of the ordinary least square regression method in order to determine the optimum regression curve between radius and velocity that fitted better the 
distribution of the collected data. The outcome for the various driving conditions is presented in Table 6.

Based on the results of Table 6, Figures 2 to 20 were generated, a thorough examination of which led to various conclusions correlating the riders' speed adjustment with the radiuses of the curves.

As it is shown in Figures 2 to 13, the impact of the light conditions and the familiarity of the riders with the routes is important. More specifically both riders tend to speed more during daytime instead of nighttime while the greatest velocities are recorded when the riders become familiar with the routes. Furthermore they speed more when the road conditions improve, according to the evaluation of Table 4 (Figures 17 to 20).

Moreover the mean velocity of the experienced rider at the repetitions with the presence of the pillion is considerably higher than the corresponding velocity of the inexperienced rider and hence, it is implied that the experienced rider perceives more efficiently the benefit of the increased weight of the system motorcycle-riderpillion which is accompanied by the increase of the side friction and therefore it permits higher speeds. This is clearly reflected in Figures $\mathbf{1 4}$ to $\mathbf{1 6}$ which compare the mean speeds of the experienced and the inexperienced rider for the various routes.

\section{Conclusions}

In the present paper we introduce a new methodology aiming to develop speed prediction equations for motorcycles. For that purpose two motorcyclists recruited who rode an instrumented bike in three different rural road sections under different driving conditions (i.e. presence of pillion, different light conditions). The ultimate target was the determination of the optimum regression curve between the curve radius' and the corresponding velocities which accomplished with the implementation of the ordinary least square method.

Within the limitations of the experiment (sites, participants, type of motorcycle) the conclusions drawn from the analysis of the recorded data, are presented below:

- In all routes driven by the two riders (apart from the route Afyssos-Afetai driven by the inexperienced rider during nighttime as shown in Figure 2), the greatest velocities are recorded during the daytime instead of nighttime repetitions (Figures 3 to 7).

- In all routes driven by the riders, both during daytime and nighttime (apart from the route Afyssos-Afetai driven by the inexperienced rider during daytime as shown in Figure 8), the greatest velocities are recorded when the riders become familiar with the routes (Figures 9 to 13). This arises from the comparison of the average velocities of the first three repetitions with the last three ones.
Table 6. Equations and coefficients of determination of OLS (ordinary Least Square) method.

\begin{tabular}{|c|c|c|}
\hline Route and riding conditions & $\begin{array}{l}\text { Equation } \\
\mathbf{V}=\alpha \cdot \mathbf{R}^{\mathbf{b}}\end{array}$ & $\mathbf{R}^{2}$ \\
\hline $\begin{array}{l}\text { A-A (poor), IXP, DL, } \\
\text { avg. of repetitions } 1 \text { to } 6\end{array}$ & $\mathrm{~V}=8.7395 \cdot \mathrm{R}^{0.3221}$ & 0.95 \\
\hline $\begin{array}{l}\text { A-A (poor), IXP, NL, } \\
\text { avg. of repetitions } 1 \text { to } 6\end{array}$ & $\mathrm{~V}=8.8669 \cdot \mathrm{R}^{0.3582}$ & 0.97 \\
\hline $\begin{array}{l}\text { M-L (satisfactory), IXP, DL, } \\
\text { avg. of repetitions } 1 \text { to } 6\end{array}$ & $\mathrm{~V}=12.888 \cdot \mathrm{R}^{0.3183}$ & 0.89 \\
\hline $\begin{array}{l}\text { M-L (satisfactory), IXP, NL, } \\
\text { avg. of repetitions } 1 \text { to } 6\end{array}$ & $\mathrm{~V}=11.277 \cdot \mathrm{R}^{0.3163}$ & 0.93 \\
\hline $\begin{array}{l}\text { N-K (excellent), IXP, DL, } \\
\text { avg. of repetitions } 1 \text { to } 6\end{array}$ & $\mathrm{~V}=15.499 \cdot \mathrm{R}^{0.3017}$ & 0.91 \\
\hline $\begin{array}{l}\text { N-K (excellent), IXP, NL, } \\
\text { avg. of repetitions } 1 \text { to } 6\end{array}$ & $\mathrm{~V}=14.044 \cdot \mathrm{R}^{0.2922}$ & 0.90 \\
\hline $\begin{array}{l}\text { A-A (poor), EXP, DL, } \\
\text { avg. of repetitions } 1 \text { to } 6\end{array}$ & $\mathrm{~V}=8.4390 \cdot \mathrm{R}^{0.3628}$ & 0.95 \\
\hline $\begin{array}{l}\text { A-A (poor), EXP, NL, } \\
\text { avg. of repetitions } 1 \text { to } 6\end{array}$ & $\mathrm{~V}=9.2203 \cdot \mathrm{R}^{0.3231}$ & 0.94 \\
\hline $\begin{array}{l}\text { M-L (satisfactory), EXP, DL, } \\
\text { avg. of repetitions } 1 \text { to } 6\end{array}$ & $\mathrm{~V}=12.550 \cdot \mathrm{R}^{0.3189}$ & 0.88 \\
\hline $\begin{array}{l}\text { M-L (satisfactory), EXP, NL, } \\
\text { avg. of repetitions } 1 \text { to } 6\end{array}$ & $\mathrm{~V}=12.568 \cdot \mathrm{R}^{0.3082}$ & 0.92 \\
\hline $\begin{array}{l}\text { N-K (excellent), EXP, DL, } \\
\text { avg. of repetitions } 1 \text { to } 6\end{array}$ & $\mathrm{~V}=14.177 \cdot \mathrm{R}^{0.3132}$ & 0.88 \\
\hline $\begin{array}{l}\text { N-K (excellent), EXP, NL, } \\
\text { avg. of repetitions } 1 \text { to } 6\end{array}$ & $\mathrm{~V}=13.187 \cdot \mathrm{R}^{0.3055}$ & 0.80 \\
\hline $\begin{array}{l}\text { A-A (poor), IXP, DL \& NL, } \\
\text { avg. of repetitions } 1 \text { to } 3\end{array}$ & $\mathrm{~V}=8.6965 \cdot \mathrm{R}^{0.3609}$ & 0.96 \\
\hline $\begin{array}{l}\text { A-A (poor), IXP, DL \& NL, } \\
\text { avg. of repetitions } 4 \text { to } 6\end{array}$ & $\mathrm{~V}=8.9161 \cdot \mathrm{R}^{0.3505}$ & 0.95 \\
\hline $\begin{array}{l}\text { M-L (satisfactory), IXP, DL \& NL, } \\
\text { avg. of repetitions } 1 \text { to } 3\end{array}$ & $\mathrm{~V}=11.123 \cdot \mathrm{R}^{0.3323}$ & 0.77 \\
\hline $\begin{array}{l}\text { M-L (satisfactory), IXP, DL \& NL, } \\
\text { avg. of repetitions } 4 \text { to } 6\end{array}$ & $\mathrm{~V}=12.975 \cdot \mathrm{R}^{0.3027}$ & 0.81 \\
\hline $\begin{array}{l}\text { N-K (excellent), IXP, DL \& NL, } \\
\text { avg. of repetitions } 1 \text { to } 3\end{array}$ & $\mathrm{~V}=15.404 \cdot \mathrm{R}^{0.2849}$ & 0.75 \\
\hline $\begin{array}{l}\text { N-K (excellent), IXP, DL \& NL, } \\
\quad \text { avg. of repetitions } 4 \text { to } 6\end{array}$ & $\mathrm{~V}=14.154 \cdot \mathrm{R}^{0.3085}$ & 0.69 \\
\hline $\begin{array}{l}\text { A-A (poor), EXP, DL \& NL, } \\
\text { avg. of repetitions } 1 \text { to } 3\end{array}$ & $\mathrm{~V}=9.9442 \cdot \mathrm{R}^{0.3362}$ & 0.92 \\
\hline $\begin{array}{l}\text { A-A (poor), EXP, DL \& NL, } \\
\text { avg. of repetitions } 4 \text { to } 6\end{array}$ & $\mathrm{~V}=8.7015 \cdot \mathrm{R}^{0.3484}$ & 0.93 \\
\hline $\begin{array}{l}\text { M-L (satisfactory), EXP, DL \& NL, } \\
\text { avg. of repetitions } 1 \text { to } 3\end{array}$ & $\mathrm{~V}=12.799 \cdot \mathrm{R}^{0.3004}$ & 0.85 \\
\hline $\begin{array}{l}\text { M-L (satisfactory), EXP, DL \& NL, } \\
\text { avg. of repetitions } 4 \text { to } 6\end{array}$ & $\mathrm{~V}=12.360 \cdot \mathrm{R}^{0.3255}$ & 0.88 \\
\hline $\begin{array}{l}\text { N-K (excellent), EXP, DL \& NL, } \\
\text { avg. of repetitions } 1 \text { to } 3\end{array}$ & $\mathrm{~V}=14.172 \cdot \mathrm{R}^{0.2997}$ & 0.74 \\
\hline $\begin{array}{l}\text { N-K (excellent), EXP, DL \& NL, } \\
\quad \text { avg. of repetitions } 4 \text { to } 6\end{array}$ & $\mathrm{~V}=13.195 \cdot \mathrm{R}^{0.3189}$ & 0.75 \\
\hline A-A (poor), IXP, Pillion & $\mathrm{V}=8.5988 \cdot \mathrm{R}^{0.3217}$ & 0.91 \\
\hline A-A (poor), EXP, Pillion & $\mathrm{V}=8.6167 \cdot \mathrm{R}^{0.3826}$ & 0.95 \\
\hline M-L (satisfactory), IXP, Pillion & $\mathrm{V}=13.210 \cdot \mathrm{R}^{0.2712}$ & 0.78 \\
\hline M-L (satisfactory), EXP, Pillion & $\mathrm{V}=13.374 \cdot \mathrm{R}^{0.2861}$ & 0.76 \\
\hline N-K (excellent), IXP, Pillion & $\mathrm{V}=16.497 \cdot \mathrm{R}^{0.2684}$ & 0.82 \\
\hline N-K (excellent), EXP, Pillion & $\mathrm{V}=15.262 \cdot \mathrm{R}^{0.3107}$ & 0.80 \\
\hline
\end{tabular}

A-A: Afyssos-Afetai, M-L: Milina-Lafkos, N-K: Neohori-Kalamaki, INX: inexperienced rider, EXP: experienced rider, DL: daylight, NL: nightlight, avg.: average. 


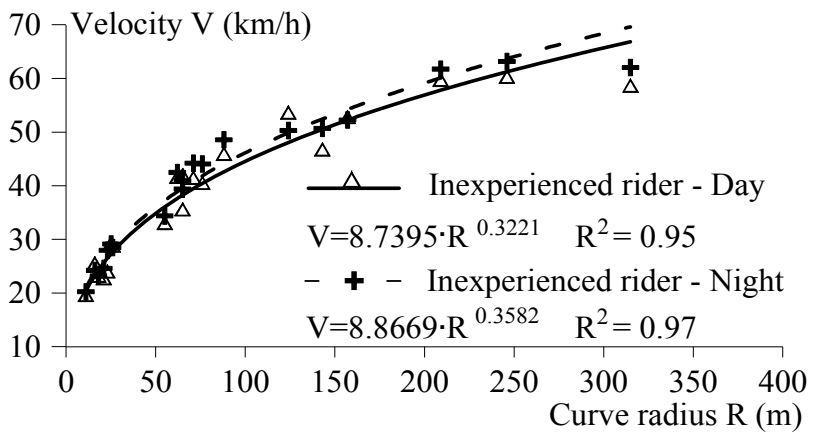

Figure 2. Velocity in relation to curve radius in the route Afyssos-Afetai (poor quality) - Inexperienced rider.

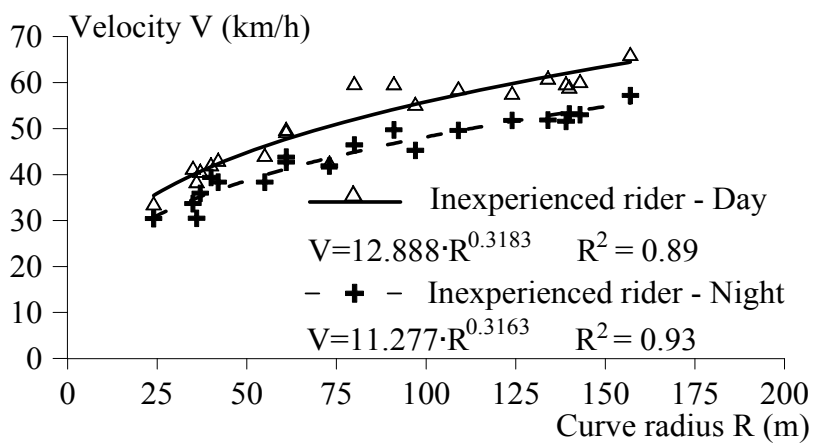

Figure 3. Velocity in relation to curve radius in the route Milina-Lafkos (satisfactory quality) - Inexperienced rider.

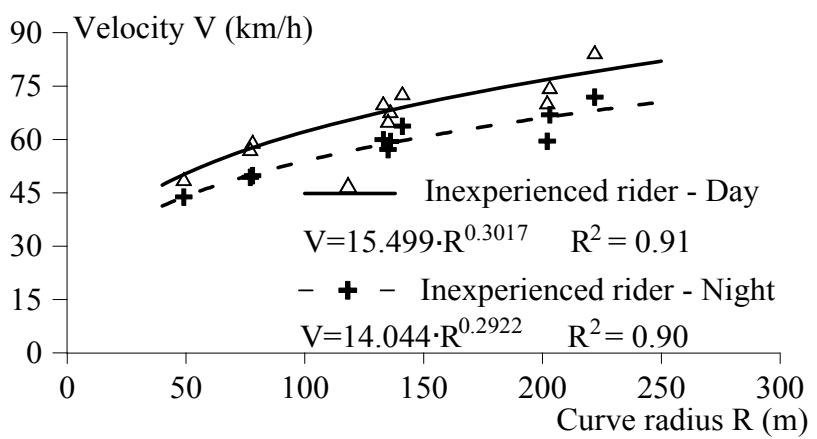

Figure 4. Velocity in relation to curve radius in the route Neoxori-Kalamaki (excellent quality) - Inexperienced rider.

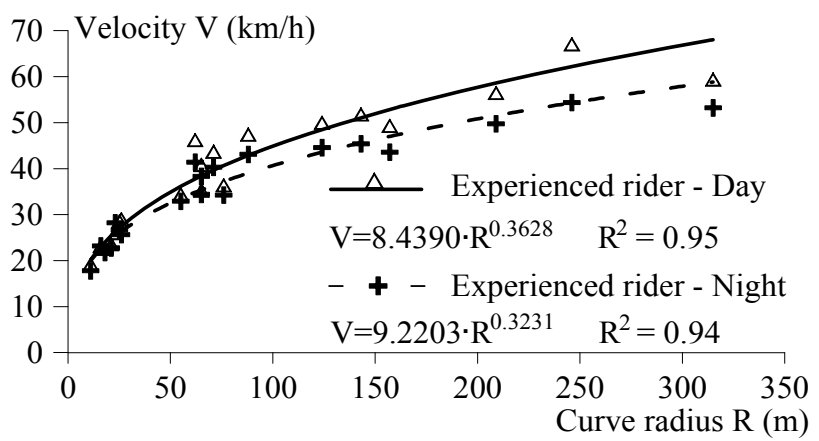

Figure 5. Velocity in relation to curve radius in the route Afyssos-Afetai (poor quality)—Experienced rider.

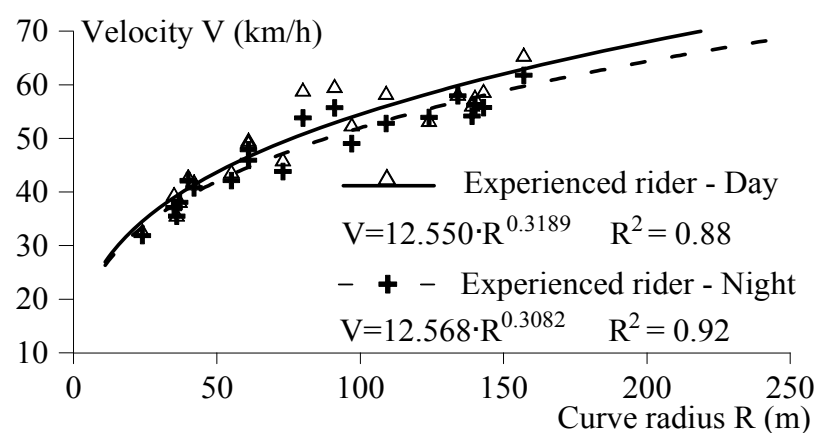

Figure 6. Velocity in relation to curve radius in the route Milina-Lafkos (satisfactory quality)—Experienced rider.

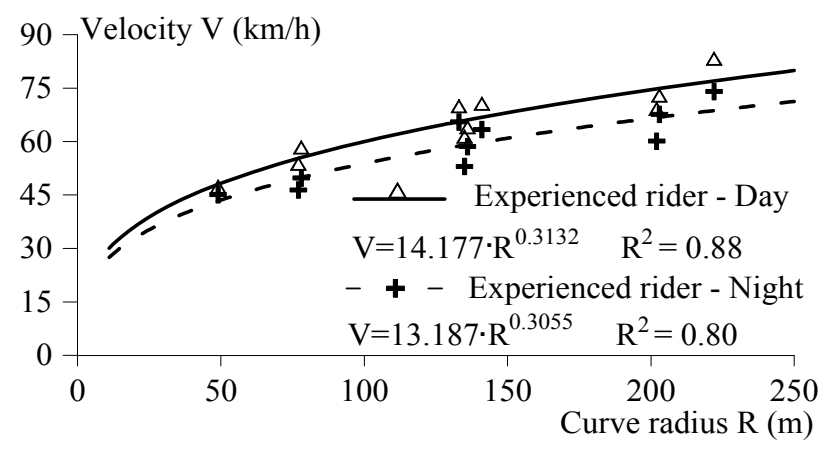

Figure 7. Velocity in relation to curve radius in the route $\mathrm{Ne}$ oxori-Kalamaki (excellent quality)—Experienced rider.

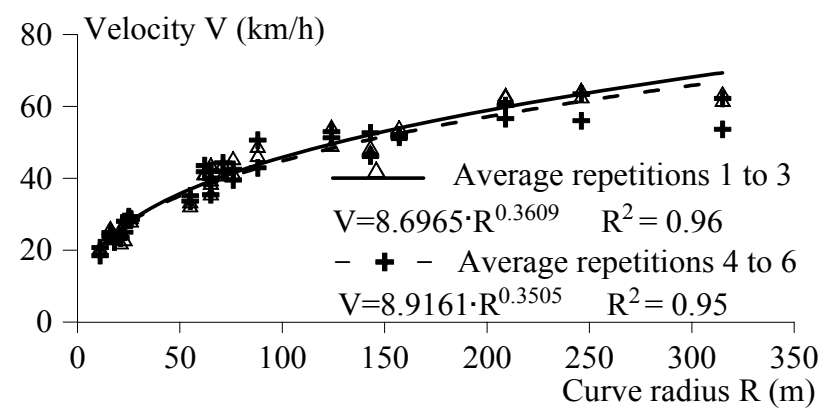

Figure 8. Velocity in relation to curve radius in the route Afyssos-Afetai (poor quality)—Familiarization of inexperienced rider with road conditions.

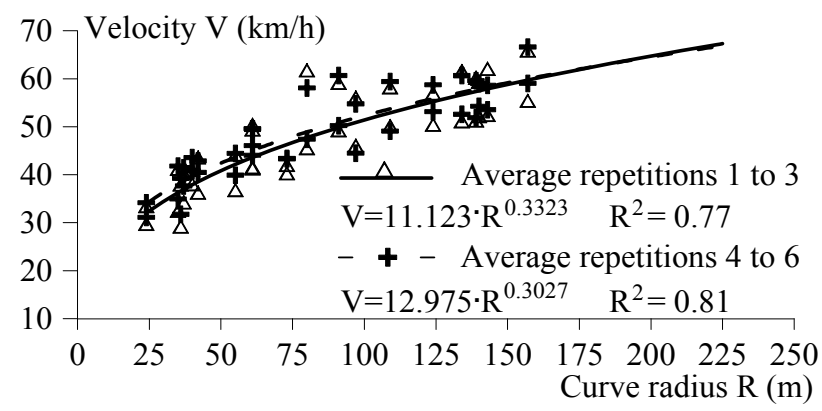

Figure 9. Velocity in relation to curve radius in the route Milina-Lafkos (satisfactory quality)-Familiarization of inexperienced rider with road conditions. 


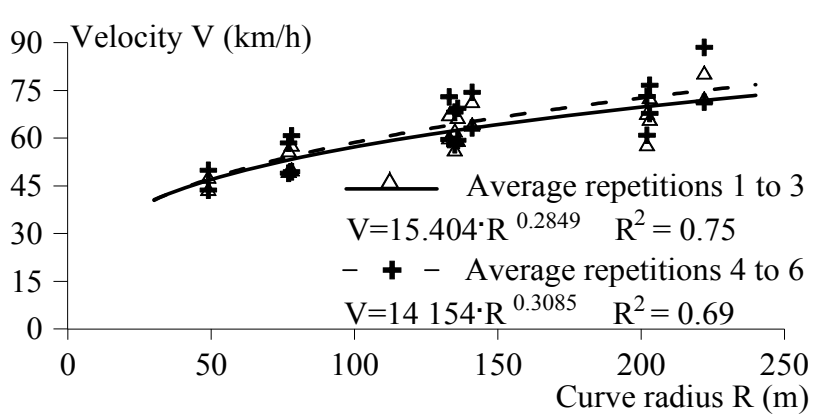

Figure 10. Velocity in relation to curve radius in the route Neoxori-Kalamaki (excellent quality)—Familiarization of inexperienced rider with road conditions.

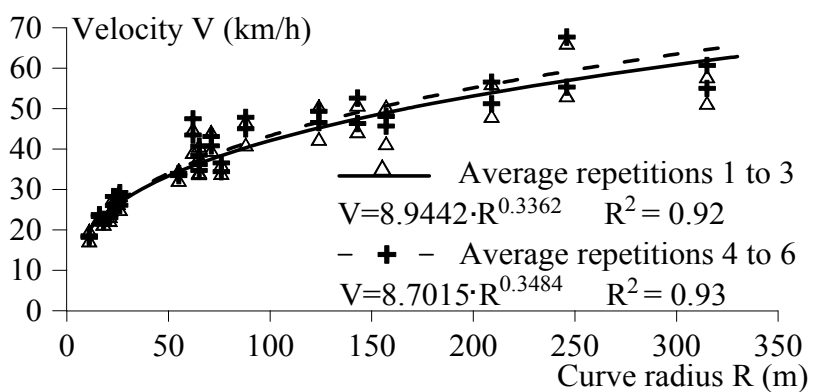

Figure 11. Velocity in relation to curve radius in the route Afyssos-Afetai (poor quality)—Familiarization of experienced rider with road conditions.

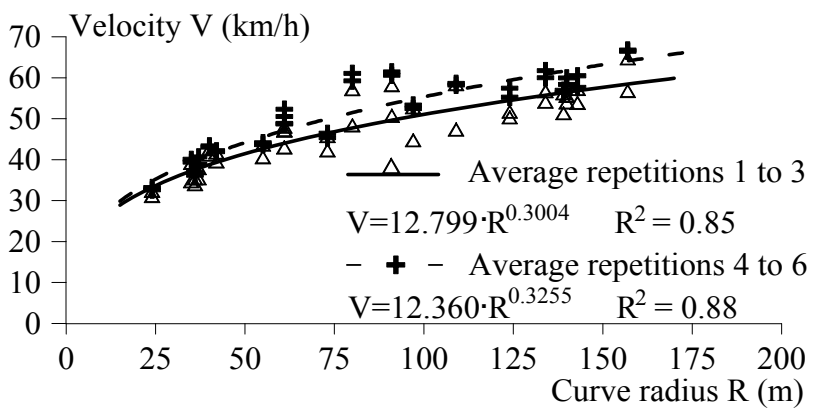

Figure 12. Velocity in relation to curve radius in the route Milina-Lafkos (satisfactory quality)_Familiarization of experienced rider with road conditions.

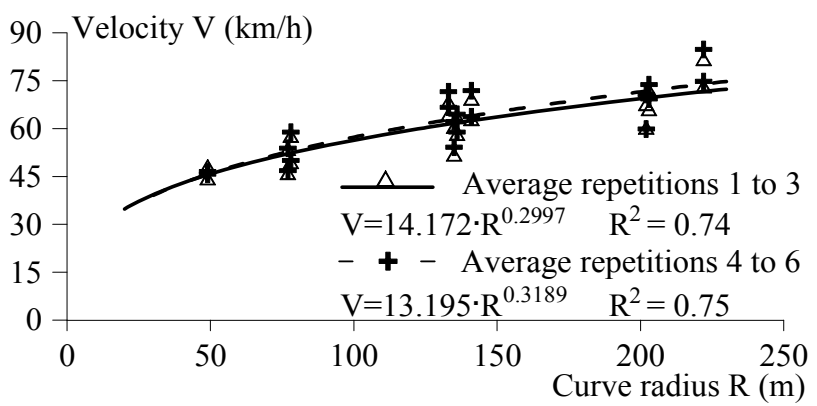

Figure 13. Velocity in relation to curve radius in the route Neoxori-Kalamaki (excellent quality)—Familiarization of experienced rider with road conditions.

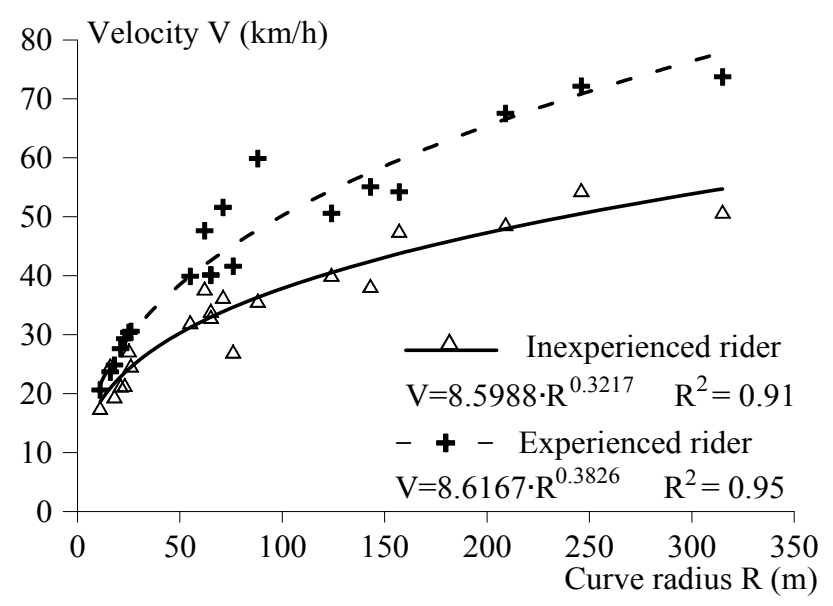

Figure 14. Velocity in relation to curve radius in the route Afyssos-Afetai (poor quality)-Experienced and inexperienced rider with the presence of pillion.

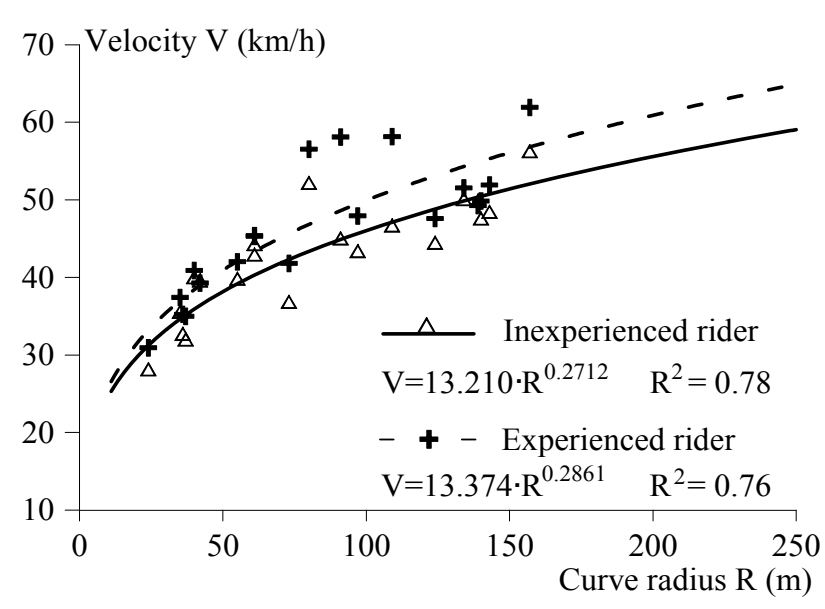

Figure 15. Velocity in relation to curve radius in the route Milina-Lafkos (satisfactory quality)—Experienced and inexperienced rider with the presence of pillion.

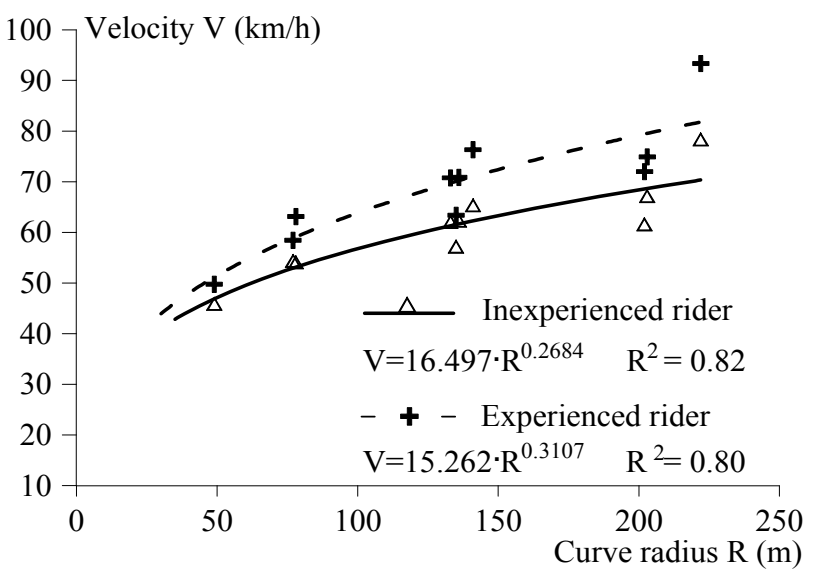

Figure 16. Velocity in relation to curve radius in the route Neoxori-Kalamaki (excellent quality)-Experienced and inexperienced rider with the presence of pillion. 


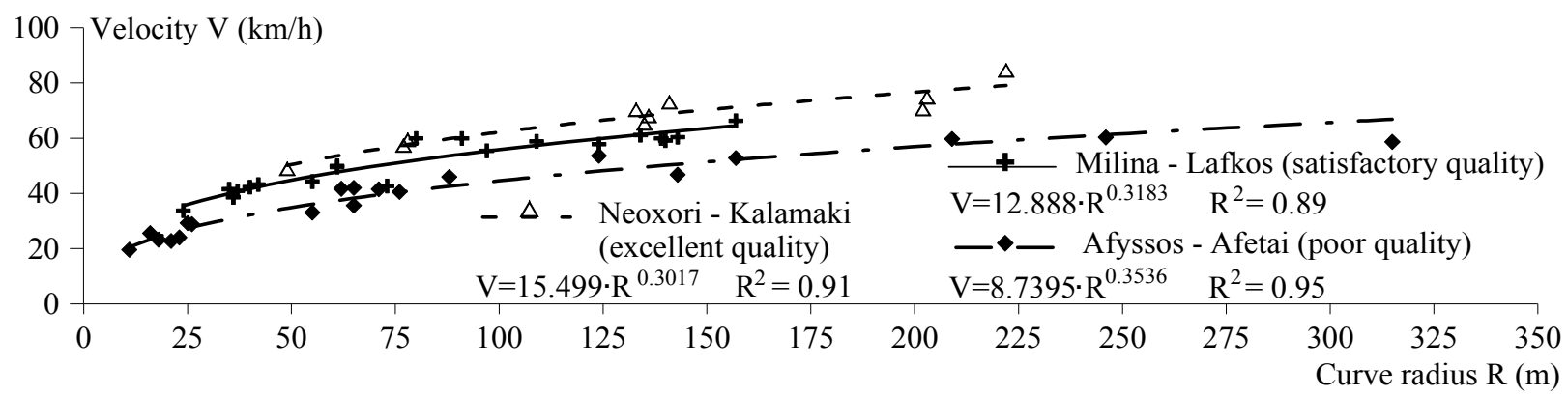

Figure 17. Velocity in relation to curve radius in all routes by inexperienced rider during daylight.

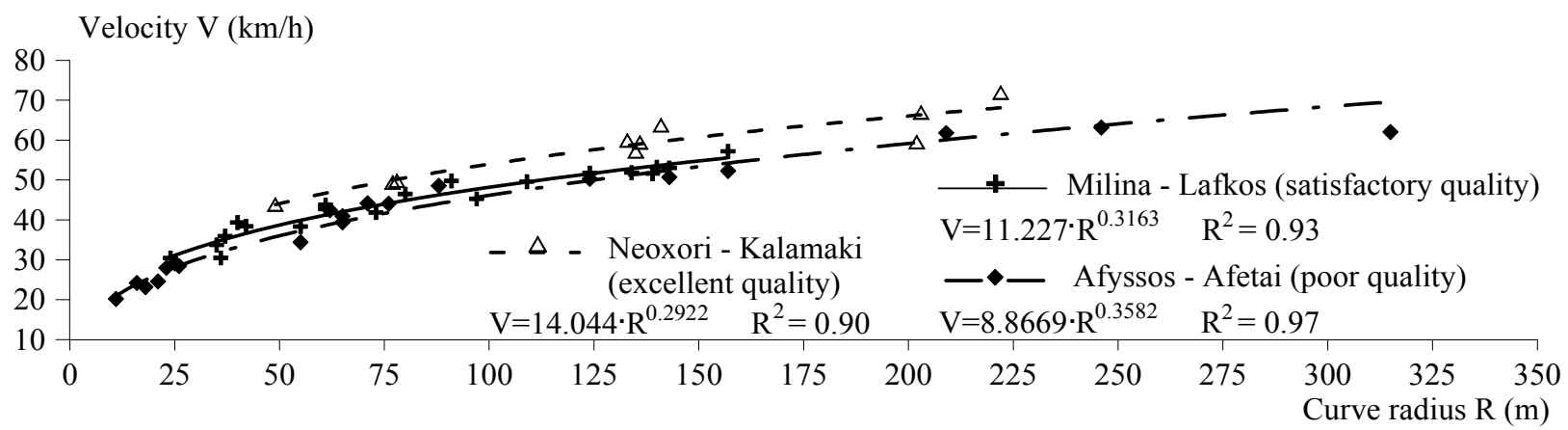

Figure 18. Velocity in relation to curve radius in all routes by inexperienced rider during nightlight.

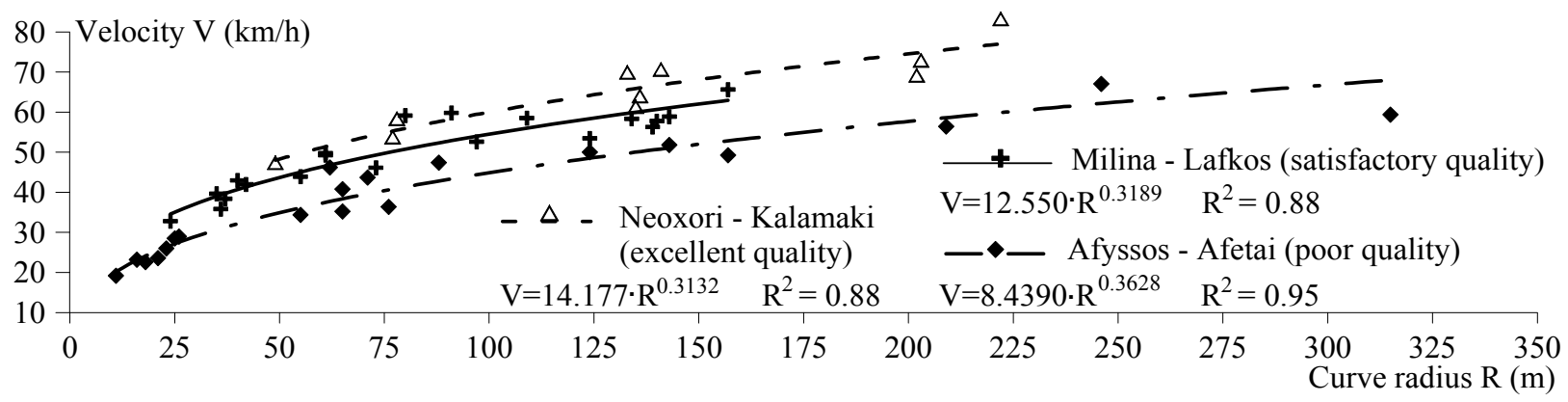

Figure 19. Velocity in relation to curve radius in all routes by experienced rider during daylight.

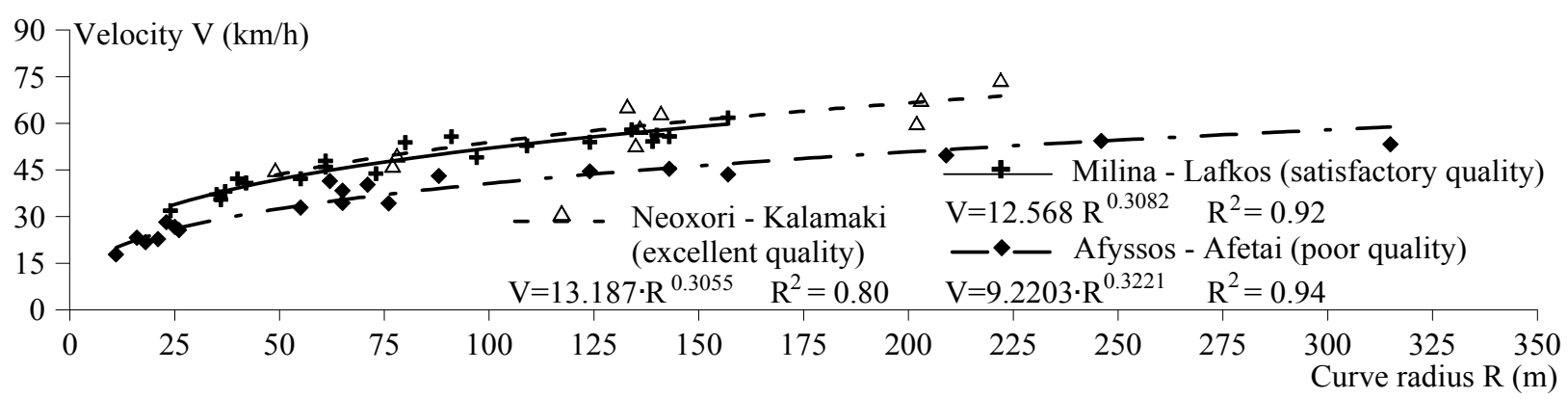

Figure 20. Velocity in relation to curve radius in all routes by experienced rider during nightlight.

- In all routes, during the repetitions with the presence of a pillion, the experienced rider speeds significant more than the inexperienced rider (Figures 14 to 16).

- Both riders either during daytime or nighttime perceive the improvement of the road conditions (as determined in Table 4) by increasing their velocities
(Figures 17 to 20).

\section{REFERENCES}

[1] N. M. Islam and P. N. Seneviratne, "Evaluation of Design Consistency of Two-Lane Rural Highways," Institute of 
Transportation Engineers Journal, Vol. 64, No. 2, 1994, pp. 28-31.

[2] A. P. Voigt and R. A. Krammes, "An Operational and Safety Evaluation of Alternative Horizontal Curve Design Approaches on Rural Two-lane Highways," Proceedings of the International Symposium on Highway Geometric Design Practices, Boston, 30 August-1 September 1995, pp. 11.1-11.8.

http://onlinepubs.trb.org/onlinepubs/circulars/ec003/ch11. pdf

[3] M. Wooldridge, K. Fitzpatrick, D. Harwood, I. Potts, L. Elefteriadou and D. Torbic, "Geometric Design Consistency on High-speed Rural Two-lane Roadways," Transportation Research Program, Washington DC, 2003. http://onlinepubs.trb.org/onlinepubs/nchrp/nchrp_rpt_502 .pdf

[4] F. Tate and S. Turner, "Road Geometry and Drivers Speed Choice," Proceedings of IPENZ Transportation Group Conference, Tauranga, 7-10 October 2007, 15p. http://www.ipenz.org.nz/ipenztg/papers/2007/C2_TateTur ner.pdf

[5] T. Esposito, R. Mauro, F Russo and G. Dell'Acqua, "Speed Prediction Models for Sustainable Road Safety Management," Procedia-Social and Behavioral Sciences, Vol. 20, 2011, pp. 568-576. doi:10.1016/j.sbspro.2011.08.063

[6] S. K. Syed Abbas, M. A. Adnan and I. R. Endut, "Exploration of 85th Percentile Operating Speed Model on Horizontal Curve: A Case Study for Two-Lane Rural Highways," Procedia-Social and Behavioral Sciences, Vol. 16, 2011, pp. 352-363. doi:10.1016/j.sbspro.2011.04.456

[7] C. R. Bennett, "A Speed Prediction Model for Rural Two-Lane Highways," Ph.D. Dissertation, University of Auckland, Auckland, 1994.

[8] A. Mazzella, F. Pinna and C. Piras, "Geostatical Approach for Operating Speed Modelling on Italian Roads," Proceedings of the 4th International Symposium on Highway Geometric Design, Transportation Research Board, Valencia, 2-5 June 2010, 14p. http://www.4ishgd.valencia.upv.es/index_archivos/61.pdf

[9] Y. D. Wong and A. Nicholson, "Driver Behaviour at Horizontal Curves: Risk Compensation and the Margin of Safety," Accident Analysis and Prevention, Vol. 24, No. 4, 1992, pp. 425-436. doi:10.1016/0001-4575(92)90053-L

[10] Transportation Research Board, "Modeling Operating
Speed-Synthesis Report," Washington DC, 2011. http://onlinepubs.trb.org/onlinepubs/circulars/ec151.pdf

[11] P. Perco, "Comparison between Powered Two Wheeler and Passenger Car Free-Flow Speeds in Urban Areas," Journal of the Transportation Research Board, No. 2074, 2008, pp. 77-84. doi:10.3141/2074-10

[12] S. F. Faezi, H. Hamid and S. R. Davoodi, "Predicting Speed Model of Horizontal Curves on Exclusive Motorcycle Lane," Australian Journal of Basic and Applied Sciences, Vol. 5, No. 5, 2011, pp. 590-598.

[13] FESTA (Field opErational teSt supporT Action), "Primer on Experimental Procedures," 2008.

https://dspace.lboro.ac.uk/dspace-jspui/bitstream/2134/57 04/1/AR2601\%20FESTA\%20D2\%203\%20Primer\%20on $\% 20$ experimental $\% 20$ procedures.pdf

[14] G. Yannis, J. Golias, E. Papadimitriou and I. Spyropoulou, "Accident Risk Analysis of Passenger Car Drivers and Two-Wheeler Riders in Greece," Proceedings of the 3rd National Conference on Road Safety, Patra, 10-11 October 2005, 16p.

[15] S. Laporte and S. Espié (coordinators), "Understanding Risk Taking Behaviour within the Context of PTW Riders," 2-Wheeler Behavior \& Safety-7th Framework Program, 2011.

http://www.2besafe.eu/sites/default/files/deliverables/2BE S D7 SocialCognitiveAndBehaviouralDifferencesOfPTW RidersWithReferenceToTheirAttitudesTowardsRiskAndSa fety.pdf

[16] F. G. Pratico and M. Giunta, "Operational and Safety Effects of Two-Lane Roads Alignment," Proceedings of the 4th International Symposium on Highway Geometric Design, Transportation Research Board, Valencia, 2-5 June 2010, 14p. http://www.4ishgd.valencia.upv.es/index_archivos/73.pdf

[17] M. Castro, J. Sanchez, N. Ardila and J. Melo, "Speed Models for Highway Consistency Analysis. A Colombian Case Study," Proceedings of the 4th International Symposium on Highway Geometric Design, Transportation Research Board, Valencia, 2-5 June 2010, 15p. http://www.4ishgd.valencia.upv.es/index_archivos/28.pdf

[18] A. Abdul-Mawjoud and G. Sofia, "Development of Models for Predicting Speed on Horizontal Curves for TwoLane Rural Highways," The Arabian Journal for Science and Engineering, Vol. 33, No. 2B, 2008, pp. 365-377. 